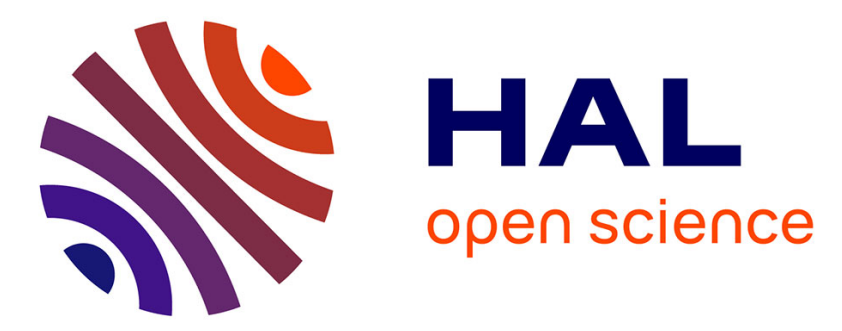

\title{
Q-branch linewidths of N2 perturbed by H2: experiments and quantum calculations from an ab initio potential.
}

Laura Gómez, Raúl Z Martínez, Dionisio Bermejo, Franck Thibault, Pierre Joubert, Béatrice Bussery-Honvault, Jeanine Bonamy

\section{To cite this version:}

Laura Gómez, Raúl Z Martínez, Dionisio Bermejo, Franck Thibault, Pierre Joubert, et al.. Q-branch linewidths of $\mathrm{N} 2$ perturbed by $\mathrm{H} 2$ : experiments and quantum calculations from an ab initio potential.. Journal of Chemical Physics, 2007, 126 (20), pp.204302. 10.1063/1.2731789 . hal-00908228

\section{HAL Id: hal-00908228 \\ https://hal.science/hal-00908228}

Submitted on 22 Nov 2013

HAL is a multi-disciplinary open access archive for the deposit and dissemination of scientific research documents, whether they are published or not. The documents may come from teaching and research institutions in France or abroad, or from public or private research centers.
L'archive ouverte pluridisciplinaire HAL, est destinée au dépôt et à la diffusion de documents scientifiques de niveau recherche, publiés ou non, émanant des établissements d'enseignement et de recherche français ou étrangers, des laboratoires publics ou privés. 


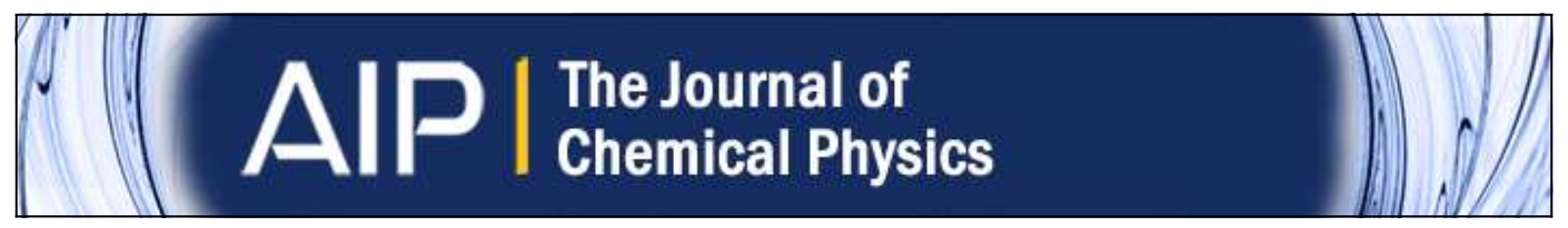

Q -branch linewidths of $\mathbf{N} 2$ perturbed by $\mathrm{H} 2$ : Experiments and quantum calculations from an ab initio potential

Laura Gómez, Raúl Z. Martínez, Dionisio Bermejo, Franck Thibault, Pierre Joubert, Béatrice Bussery-Honvault, and Jeanine Bonamy

Citation: The Journal of Chemical Physics 126, 204302 (2007); doi: 10.1063/1.2731789

View online: http://dx.doi.org/10.1063/1.2731789

View Table of Contents: http://scitation.aip.org/content/aip/journal/jcp/126/20?ver=pdfcov

Published by the AIP Publishing

\section{AlP Re-register for Table of Content Alerts}




\title{
Q-branch linewidths of $\mathrm{N}_{2}$ perturbed by $\mathrm{H}_{2}$ : Experiments and quantum calculations from an $a b$ initio potential
}

\author{
Laura Gómez, Raúl Z. Martínez, and Dionisio Bermejo \\ Instituto de Estructura de la Materia, CSIC, Serrano 123, 28006 Madrid, Spain \\ Franck Thibault \\ Laboratoire PALMS, UMR CNRS 6627, Université de Rennes I, 35042 Rennes Cedex, France \\ Pierre Joubert, ${ }^{\text {a) }}$ Béatrice Bussery-Honvault, and Jeanine Bonamy \\ Institut UTINAM, UMR CNRS 6213, Université de Franche-Comté, 25030 Besançon Cedex, France
}

(Received 22 February 2007; accepted 26 March 2007; published online 22 May 2007)

In this work the authors present an experimental and theoretical study about the $Q$-branch lines' broadening coefficients of $\mathrm{N}_{2}$ perturbed by $\mathrm{H}_{2}$. Experimental values for these parameters have been obtained at 440 and $580 \mathrm{~K}$, and quantum calculations have been performed using a new ab initio potential energy surface, obtained by quantum chemistry methods. The results of these calculations are compared to experimental data obtained previously at 77 and $298 \mathrm{~K}$ [L. Gomez et al., Mol. Phys. 104, 1869 (2006)] and to the present measurements. A satisfactory agreement is obtained for the whole range of temperatures used in the experiments. (C) 2007 American Institute of Physics. [DOI: $10.1063 / 1.2731789$ ]

\section{INTRODUCTION}

In the last decades, laser spectroscopic techniques have been greatly improved, in particular, their applications to atmospheric monitoring and combustion diagnostics. But, a reliable interpretation of the quantitative measurements requires an accurate knowledge of the collisional parameters such as the line shifting and line broadening coefficients of the molecular species constituting these media.

The nitrogen molecule is one of the major active molecules used for thermometry in combustion media. This is why $\mathrm{N}_{2}$ has often been used as a probe molecule for the determination of local temperature or concentration. Numerous studies concerning pure $\mathrm{N}_{2}$ systems have been carried out $^{1,2}$ using Raman spectroscopy. Precise studies of the collisional processes involving $\mathrm{N}_{2}$ as an active molecule are also essential in atmospheric applications at lower temperatures. However, apart from pure $\mathrm{N}_{2}$ (Refs. 1 and 2) or $\mathrm{N}_{2}-\mathrm{H}_{2} \mathrm{O}$ (Ref. 3) systems, few data are available in the literature involving $\mathrm{N}_{2}$ as active molecule.

In a previous work, ${ }^{4}$ we have presented for the first time the experimental and theoretical values for the collisional line broadening coefficients of the $\mathrm{N}_{2}-\mathrm{H}_{2}$ system. The measurements were obtained from high resolution stimulated Raman spectra recorded in Madrid at 77 and $298 \mathrm{~K}$. Theoretical calculations between 77 and $500 \mathrm{~K}$ were performed using the semiclassical Robert-Bonamy (RB) model. ${ }^{5}$ At room temperature, both experimental and theoretical values showed a good agreement using an adjusted value for the kinetic diameter of the atom-atom potential used in the RB model. However, we observed a discrepancy at $77 \mathrm{~K}$ attributed to orbiting collisions, which are not taken into account in the semiclassical model.

${ }^{a)}$ Fax: +33 3816664 75. Electronic mail: pierre.joubert@univ-fcomte.fr
In this work, we present new measurements of $\mathrm{N}_{2}$ $Q$-branch lines broadened by $\mathrm{H}_{2}$ at 440 and $580 \mathrm{~K}$, enlarging the range of temperatures of previous experiments. ${ }^{4}$ As in Ref. 4 the experimental technique used is stimulated Raman loss spectroscopy. ${ }^{6}$

Furthermore, in order to compare with experimental results, we have built up a new ab initio potential energy surface (PES), using quantum chemistry methods, on which quantum calculations of the pressure broadening cross sections for $\mathrm{N}_{2}-\mathrm{H}_{2}$ have been performed.

In the following section we briefly describe the experimental device used in this study. In Sec. III we present the method employed for the $a b$ initio calculations and the fitting procedure of the $\mathrm{N}_{2}-\mathrm{H}_{2}$ PES. Section IV is devoted to the pure quantum close coupling calculations. Results and discussions are included in Sec. V, and finally, concluding remarks and perspectives are given in Sec. VI.

\section{EXPERIMENT}

Experimental details have already been described in previous papers ${ }^{4,6}$ and, therefore, only the high temperature Raman cell used for the measurements at 440 and $580 \mathrm{~K}$ will be given here. Figure 1 shows a scheme of the cell: a $60 \mathrm{~cm}$ long, $4 \mathrm{~cm}$ external diameter, and $1.7 \mathrm{~cm}$ internal diameter 316 stainless steel cylinder $\mathrm{C} 1$ constitutes the main body of the cell. $1 \mathrm{in}$. diameter fused silica windows $\mathrm{W}$ are fitted at both ends using isolast 8325 o-rings for $440 \mathrm{~K}$ and Loctite 5398 glue for $580 \mathrm{~K}$. A perpendicular tube at the center of the cell houses a jacket for a thermocouple $\mathrm{T} 1$ and a pipe $\mathrm{P}$ for gas transfer. At $20 \mathrm{~cm}$ from the center another tube houses a second jacket for a second thermocouple T2 in order to control the temperature gradients. The main cell body is packed into four $68 \Omega$ resistor muffles $M$. The total length of the four muffle assembly is $82 \mathrm{~cm}$, exceeding the length 


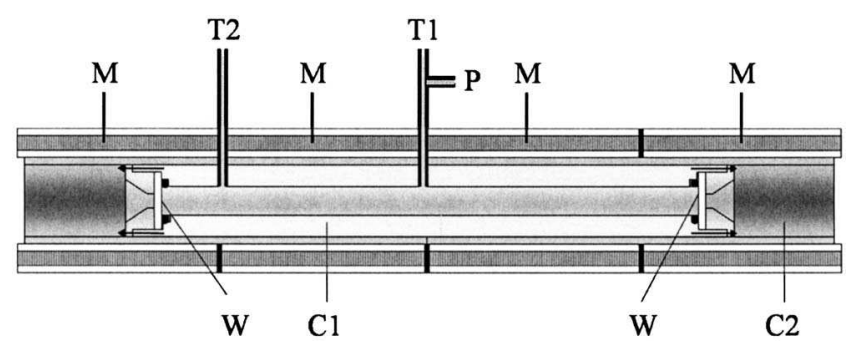

FIG. 1. Scheme of the high temperature Raman cell used for the measurements at 440 and $580 \mathrm{~K}$.

of the main cell body by $22 \mathrm{~cm}$ in order to reduce as much as possible the temperature gradients between the window regions and the central part of the cell. A third 316L stain steel cylinder $\mathrm{C} 2$ is placed between the main body and the muffles, in close contact with both, in order to distribute as well as possible the heat flow in the border regions between muffles. The whole assembly is packed into a block of bored refractory bricks to provide thermal insulation.

The heating procedure is as follows: The desired temperature is set in a temperature controller built for this purpose. The controller compares the reading of the thermocouples with the target temperature, and a microprocessor determines the initial heating time of the four resistors, which are, at this stage, connected in parallel. The heating profile used by the microprocessor has been previously determined through measurements performed using the same cell in order to estimate the thermal inertia of the system. After this initial heating stage the reading of thermocouples should be approaching the desired value, and the system enters a second stage in which the heating is stopped (resistor voltage set to zero) while the temperature in the cell main body continues to slowly rise due to the inertia of the muffles.

Once the operation regime has been reached (typically in $60 \mathrm{~min}$ for about $500 \mathrm{~K}$ ), the maximum temperature fluctuation over $3 \mathrm{~h}$ operation is estimated to be less than $1{ }^{\circ} \mathrm{C}$. The gradient between thermocouples during this period is also estimated to be less than $1^{\circ} \mathrm{C}$.

\section{A NEW $\mathrm{N}_{2}-\mathrm{H}_{2}$ INTERMOLECULAR POTENTIAL}

Motivated by the scarce and no global previous works ${ }^{7-9}$ on the ground state potential energy surface of $\mathrm{N}_{2}-\mathrm{H}_{2}$, we present here new ab initio calculations for this state in order to determine the potential energy of this dimer in a large range of geometries.

\section{A. $A b$ initio calculations}

First, we have used two different ab initio methods and several basis sets to test their influence on the binding energies. Indeed, as we are dealing with a van der Waals interaction, the binding energies are small and the precision on the energy must be higher than one wave number. For that, we have carefully chosen size-consistent methods: the symmetry-adapted perturbation theory ${ }^{10}$ (SAPT) and the state of the art coupled cluster method including single and double excitations with perturbative treatment of triple excitations $[\mathrm{CCSD}(\mathrm{T})]$. Three basis sets have been tested: augmented correlation consistent polarized triple zeta or quadruple zeta valence (aug-cc-pVTZ/aug-cc-pVQZ) basis sets and the polarization optimized one of Sadlej. All of them have been completed with a $(3 s 3 p 2 d 1 f)$ set of midbond functions as proposed by Tao and Pan. ${ }^{11}$ The aug-cc-pVTZ basis consists of $[5 s 4 p 3 d 2 f]$ contracted Gaussian functions for $\mathrm{N}$ and $[4 s 3 p 2 d]$ for $\mathrm{H}$, the aug-cc-pVQZ set is contracted to $[6 s 5 p 4 d 3 f 2 g]$ for $\mathrm{N}$ and $[5 s 4 p 3 d 2 f]$ for $\mathrm{H}$, and the Sadlej basis set has $[5 s 3 p 2 d 1 f]$ contracted Gaussian functions for $\mathrm{N}$ and $[3 s 2 p]$ for $\mathrm{H}$. In order to obtain accurate intermolecular energies with the $\operatorname{CCSD}(\mathrm{T})$ method, we have to correct the $\operatorname{CCSD}(\mathrm{T})$ energies from the basis set superposition errors (BSSEs), while the SAPT method gives BSSE-free energies. The BSSE correction has been realized following the Boys and Bernardi approach. ${ }^{12}$ For that, three calculations are required at each geometry: (1) $E_{\mathrm{AB}}(\mathrm{AB})$, the energy of the dimer in the $\mathrm{AB}$ dimer basis; (2) $E_{\mathrm{AB}}(\mathrm{A})$, the energy of the monomer $\mathrm{A}$ in the dimer basis; and (3) $E_{\mathrm{AB}}(\mathrm{B})$, similarly for the monomer B. The BSSE-free dimer energies are then obtained by

$$
V^{\mathrm{CCSD}(\mathrm{T})}=E_{\mathrm{AB}}(\mathrm{AB})-E_{\mathrm{AB}}(\mathrm{A})-E_{\mathrm{AB}}(\mathrm{B}) .
$$

TABLE I. Ab initio characteristics of the $\mathrm{N}_{2}-\mathrm{H}_{2}$ intermolecular potential for selected conformations of the dimer using different ab initio methods and several basis sets: (a) $\operatorname{CCSD}(\mathrm{T})$ with aug-cc-pVTZ basis sets, (b) CCSD(T) with aug-cc-pVQZ basis sets, (c) CCSD(T) with Sadlej basis sets augmented with mid bond functions (MBFs), (d) SAPT with Sadlej basis sets+MBF, and (e) SAPT with aug-cc-pVTZ basis sets. $\Delta_{1}=c-d$ and $\Delta_{2}=$ d-e.

\begin{tabular}{|c|c|c|c|c|c|c|c|c|c|}
\hline \multirow[b]{2}{*}{$\theta_{\mathrm{A}}^{\mathrm{N}_{2}}(\mathrm{deg})$} & \multirow[b]{2}{*}{$\theta_{\mathrm{B}}^{\mathrm{H}_{2}}(\mathrm{deg})$} & \multirow[b]{2}{*}{$\varphi(\operatorname{deg})$} & \multirow[b]{2}{*}{$R(\AA)$} & \multicolumn{5}{|c|}{ Potential energy $\left(\mathrm{cm}^{-1}\right)$} & \multirow[b]{2}{*}{$\Delta_{1} / \Delta_{2}$} \\
\hline & & & & (a) & (b) & (c) & (d) & (e) & \\
\hline \multirow[t]{2}{*}{0} & 0 & 0 & 4.02 & -73.12 & -73.46 & -73.78 & -69.74 & & -4.0 \\
\hline & & & 4.23 & & & & -63.06 & -65.45 & +2.4 \\
\hline \multirow[t]{2}{*}{90} & 90 & 0 & 3.49 & -58.47 & -58.92 & -58.48 & -61.51 & & +3.0 \\
\hline & & & 3.70 & & & & -54.58 & -51.19 & -3.4 \\
\hline 90 & 90 & 90 & 3.49 & -48.29 & -48.76 & -49.13 & -51.16 & & +2.0 \\
\hline 90 & 0 & 0 & 3.70 & -31.77 & -32.12 & -32.59 & -34.77 & -30.00 & $+2.2 /-4.8$ \\
\hline 0 & 90 & 0 & 4.23 & -19.49 & -19.43 & -19.48 & -19.00 & & -0.5 \\
\hline 45 & 45 & 0 & 3.92 & -27.12 & -27.38 & -28.39 & -27.41 & & -1.0 \\
\hline 22.5 & 67.5 & 0 & 4.13 & -21.80 & & -22.31 & -21.27 & & -1.0 \\
\hline
\end{tabular}


We compare in Table I the potential energies obtained with the different methods and basis sets for selected dimer conformations. The conformations are characterized by four internal coordinates $\left(R, \theta_{\mathrm{A}}, \theta_{\mathrm{B}}, \varphi\right)$, where $R$ is the intermolecular distance between the center of masses of both molecules, thus $\mathbf{R}$ is the oriented collisional axis (from $\mathrm{N}_{2}$ to $\left.\mathrm{H}_{2}\right) . \theta_{\mathrm{A}}$ and $\theta_{\mathrm{B}}$ define the orientations of the $\mathrm{N}_{2}$ and $\mathrm{H}_{2}$ molecules, respectively, relative to this axis, and finally $\varphi$ defines the relative rotation about this axis. The diatomics have been treated as rigid and fixed at their vibrationally ground state distance, $r_{0}=2.074 \mathrm{bohr}$ for $\mathrm{N}_{2}$ and $r_{0}$ $=1.449$ bohr for $\mathrm{H}_{2}$.

From columns (a), (b), and (c) of Table I, we note that the $\operatorname{CCSD}(\mathrm{T})$ method gives similar energies with the three selected basis sets that agree to better than $1 \mathrm{~cm}^{-1}$, though the Sadlej basis is much smaller in size. Equivalent quantities obtained with the SAPT method as given by the $\Delta_{2}$ values show stronger differences (up to $\sim 5 \mathrm{~cm}^{-1}$ ). The differences between the $\operatorname{CCSD}(\mathrm{T})$ and the SAPT values using the Sadlej basis are given by the $\Delta_{1}$ quantity. We note that the use of a larger basis set (as given by $\Delta_{2}$ ) partly compensates $\Delta_{1}$ (as $\Delta_{2}$ and $\Delta_{1}$ have opposite signs). Nevertheless, only a few calculations have been conducted with the SAPT method and the aug-cc-pVTZ basis due to the difficulty of SAPT to converge with large basis sets, while the computational time grows up to several hours per point. Following these preliminary tests which give an accuracy of $4-5 \mathrm{~cm}^{-1}$ in the worst cases, we have selected the CCSD(T) method and the Sadlej basis set augmented with midbond functions to generate a regular grid of $a b$ initio points in order to get the global PES. The CCSD(T) calculations have been done with the MOLPRO package. ${ }^{13} 1575 a b$ initio points have been evaluated on a $\left(R, \theta_{\mathrm{A}}, \theta_{\mathrm{B}}, \varphi\right)$ grid of $R=[5.0,6.0,7.0,8.0,9.0,14.0,20.0]$ (in bohr), $\theta_{\mathrm{A}}=\theta_{\mathrm{B}}=\left[0.0^{\circ}, 22.5^{\circ}, 45.0^{\circ}, 67.5^{\circ}, 90.0^{\circ}\right]$, and $\varphi$ $=\left[0.0^{\circ}, 22.5^{\circ}, 45.0^{\circ}, 67.5^{\circ}, 90.0^{\circ}, 112.5^{\circ}, 135.0^{\circ}, 157.5^{\circ}\right.$, $\left.180.0^{\circ}\right]$.

\section{B. Analytical fit of the potential energy surface}

In order to analytically reproduce the above calculated points, we decomposed the intermolecular energies as follows:

$$
E\left(R, \theta_{\mathrm{A}}, \theta_{\mathrm{B}}, \varphi\right)=E_{\mathrm{sh}}\left(R, \theta_{\mathrm{A}}, \theta_{\mathrm{B}}, \varphi\right)+E_{\mathrm{as}}\left(R, \theta_{\mathrm{A}}, \theta_{\mathrm{B}}, \varphi\right),
$$

where $E_{\mathrm{sh}}$ and $E_{\mathrm{as}}$ represent, respectively, the short range contribution and the asymptotic long range part of the potential energy.

The short range contribution is given by

$$
E_{\mathrm{sh}}\left(R, \theta_{\mathrm{A}}, \theta_{\mathrm{B}}, \varphi\right)=G\left(R, \theta_{\mathrm{A}}, \theta_{\mathrm{B}}, \varphi\right) e^{D\left(\theta_{\mathrm{A}}, \theta_{\mathrm{B}}, \varphi\right)-B\left(\theta_{\mathrm{A}}, \theta_{\mathrm{B}}, \varphi\right) R},
$$

where $G$ is a polynomial in $R$ with the coefficients depending on the angles, and the exponential terms are assumed in the form

$$
D\left(\theta_{\mathrm{A}}, \theta_{\mathrm{B}}, \varphi\right)=\sum_{L_{\mathrm{A}}, L_{\mathrm{B}}, L} d^{L_{\mathrm{A}}, L_{\mathrm{B}}, L} A_{L_{\mathrm{A}} L_{\mathrm{B}} L}\left(\theta_{\mathrm{A}}, \theta_{\mathrm{B}}, \varphi\right),
$$

$$
B\left(\theta_{\mathrm{A}}, \theta_{\mathrm{B}}, \varphi\right)=\sum_{L_{\mathrm{A}}, L_{\mathrm{B}}, L} b^{L_{\mathrm{A}}, L_{\mathrm{B}}, L_{A}} A_{L_{\mathrm{A}} L_{\mathrm{B}} L}\left(\theta_{\mathrm{A}}, \theta_{\mathrm{B}}, \varphi\right) .
$$

The angular functions $A_{L_{\mathrm{A}} L_{\mathrm{B}} L}\left(\theta_{\mathrm{A}} \theta_{\mathrm{B}}, \varphi\right)$ are defined in the case of two linear molecules by normalized product of spherical harmonics for monomers $\mathrm{A}$ and $\mathrm{B}$ as

$$
\begin{aligned}
& A_{L_{\mathrm{A}} L_{\mathrm{B}} L}\left(\theta_{\mathrm{A}}, \theta_{\mathrm{B}}, \varphi\right) \\
& =\left(\frac{2 L+1}{4 \pi}\right)^{1 / 2} \sum_{m}\left\langle L_{\mathrm{A}} m L_{\mathrm{B}}-m \mid L 0\right\rangle \\
& \quad \times Y_{L_{\mathrm{A}}}^{m}\left(\theta_{\mathrm{A}}, 0\right) Y_{L_{\mathrm{B}}}^{-m}\left(\theta_{\mathrm{B}}, \varphi\right),
\end{aligned}
$$

where $Y_{L_{\mathrm{A}}}^{m}$ and $Y_{L_{\mathrm{B}}}^{-m}$ are ordinary spherical harmonics, $\langle\cdots \mid \cdots\rangle$ is a Clebsch-Gordan coefficient, and $|m| \leqslant \min \left(L_{\mathrm{A}}, L_{\mathrm{B}}\right)$.

The long range part of the potential is accounted for by the term

$$
\begin{aligned}
E_{\mathrm{as}} & \left(R, \theta_{\mathrm{A}}, \theta_{\mathrm{B}}, \varphi\right) \\
\quad & \sum_{L_{\mathrm{A}}, L_{\mathrm{B}}, L, n} f_{n}\left(B\left(\theta_{\mathrm{A}}, \theta_{\mathrm{B}}, \varphi\right) R\right) \frac{C_{n}^{L_{\mathrm{A}} L_{\mathrm{B}} L}}{R^{n}} A_{L_{\mathrm{A}} L_{\mathrm{B}} L}\left(\theta_{\mathrm{A}}, \theta_{\mathrm{B}}, \varphi\right),
\end{aligned}
$$

where $f_{n}\left(B\left(\theta_{\mathrm{A}}, \theta_{\mathrm{B}}, \varphi\right) R\right)$ are damping functions given by Tang and Toennies. ${ }^{14}$ The van der Waals constants $C_{n}^{L_{\mathrm{A}}, L_{\mathrm{B}}, L}$ are sums of the electrostatic, induction, and dispersion contributions obtained from the properties (multipole moments and static and dynamic polarizabilities) of the isolated monomers. The monomer multipole moments $\left(Q_{L_{\mathrm{A}}}, Q_{L_{\mathrm{B}}}\right)$ and dynamic polarizabilities have been evaluated up to the MBPT2 level. Then, the dispersion and induction coefficients are generated from the reducible frequency-dependent polarizabilities of each monomer followed by an integration over the imaginary frequency. All the asymptotic calculations and fitting procedure have been realized following the Bukowski et al. approach ${ }^{15}$ as proposed in the related computer code. ${ }^{16}$ $b^{L_{\mathrm{A}}, L_{\mathrm{B}}, L}$ and $d^{L_{\mathrm{A}}, L_{\mathrm{B}}, L}$ are coefficients obtained from the fit. The potential and the coefficients are available as a supplementary electronic support (EPAPS Ref. 28).

After a minimization of the root mean square (rms) quantity between the fitted and the $a b$ initio energies, based on a nonlinear least square algorithm, we have obtained a $\mathrm{rms}$ of $0.01 \mathrm{kcal} / \mathrm{mol}$ for the global fit.

\section{CALCULATIONS OF PRESSURE BROADENING CROSS SECTIONS}

Pressure broadening cross sections have been derived ${ }^{17,18}$ from binary scattering $S$-matrix elements provided by MOLSCAT (Ref. 19) quantum dynamical code. Therefore, the impact approximation is assumed. ${ }^{17,20,21}$ The coupled equations were solved by means of the hybrid $\log$ derivative-Airy propagator of Alexander and Manolopoulos. ${ }^{22}$ The propagation is carried out with the diabatic modified log-derivative method from a minimum distance of $2 \AA$ to an intermediate one of $15 \AA$ and with the Airy method up to a maximum intermolecular distance $R$ $=20 \AA$. Convergence in the cross sections is typically reached for total angular momentum $J$ varying approximately from 35 to 60 for kinetic energies between 68 and $513 \mathrm{~cm}^{-1}$. Here $\vec{J}=\vec{j}_{\mathrm{AB}}+\vec{l}$, in which $\vec{j}_{\mathrm{AB}}$ is the composed an- 
gular momentum formed by the two molecules and $\vec{l}$ is associated with the relative motion of the colliding pair. In order to economize CPU time, the analytical form of the present $a b$ initio PES is not directly implemented in MOLSCAT but projected over 15 bispherical harmonics, ${ }^{23}$

$$
V\left(R, \theta_{\mathrm{A}}, \theta_{\mathrm{B}}, \varphi\right)=\sum_{L_{\mathrm{A}}, L_{\mathrm{B}}, L} v_{L_{\mathrm{A}}, L_{\mathrm{B}}, L}(R) \times A_{L_{\mathrm{A}} L_{\mathrm{B}} L}\left(\theta_{\mathrm{A}}, \theta_{\mathrm{B}}, \varphi\right),
$$

in which $L_{\mathrm{A}}, L_{\mathrm{B}}$, and $L$ are even because the colliding pair is formed of homonuclear molecules and $\left|L_{\mathrm{A}}-L_{\mathrm{B}}\right| \leqslant L \leqslant \mid L_{\mathrm{A}}$ $+L_{\mathrm{B}} \mid$. Note that this implies $\Delta j_{\mathrm{A}}=\Delta j_{\mathrm{B}}=0, \pm 2, \ldots$. The radial coefficients $v_{L_{\mathrm{A}}, L_{\mathrm{B}}, L}(R)$ were obtained through GaussLegendre quadratures over $\theta_{\mathrm{A}}$ and $\theta_{\mathrm{B}}$ and by a Chebyshev quadrature over $\varphi .^{24}$

All energetically open rotational levels $\left(j_{\mathrm{A}}, j_{\mathrm{B}}\right)$ and at least four asymptotically closed levels, defined by $E\left(j_{\mathrm{A}}, j_{\mathrm{B}}\right)$ $=B_{\mathrm{A}} j_{\mathrm{A}}\left(j_{\mathrm{A}}+1\right)+B_{\mathrm{B}} j_{\mathrm{B}}\left(j_{\mathrm{B}}+1\right)$ in the rigid rotor approximations with $B_{\mathrm{A}}=1.998 \mathrm{~cm}^{-1}$ (for $\mathrm{N}_{2}$ ) and $B_{\mathrm{B}}=60.000 \mathrm{~cm}^{-1}$ (for $\mathrm{H}_{2}$ ), were included in the rotational basis to perform the scattering calculations for each total energy. Both nitrogen molecules and hydrogen molecules are composed of two noninterconverting species in our experiment. Natural $\mathrm{nN}_{2}$ is a 2:1 mixture of ortho- $\left(j_{\mathrm{A}}\right.$ even $)$ and para- $\left(j_{\mathrm{A}}\right.$ odd $)$ species, while natural $\mathrm{nH}_{2}$ is a 3:1 mixture of $\mathrm{oH}_{2}$ and $\mathrm{pH}_{2}$ species with odd and even $j_{\mathrm{B}}$, respectively.

Finally, since we study isotropic Raman lines in the rigid rotor approximation, the reader should recall that pressure broadening cross sections are nothing but a sum of two-body rotational state to state cross sections $\sigma\left(j_{\mathrm{A}}, j_{\mathrm{B}} ; E_{\mathrm{kin}}\right)$ $=\sum_{j_{\mathrm{A}}^{\prime}, j_{\mathrm{B}}^{\prime}} \sigma\left(j_{\mathrm{A}} j_{\mathrm{B}} \rightarrow j_{\mathrm{A}}^{\prime} j_{\mathrm{B}}^{\prime}\right)$.

Pressure broadening cross sections were calculated over a grid of kinetic energies 5, 15, 30, 50, 55, 60, 65, 68, 75, 80, $85,90,120,160,210,263.5,389$, and $513 \mathrm{~cm}^{-1}$. The close coupling (CC) method is used for kinetic energy up to $389 \mathrm{~cm}^{-1}$. In fact, the computational time remains reasonable up to this energy. The coupled states (CS) method is used to economize CPU time only for the highest energy considered, namely, $513 \mathrm{~cm}^{-1}$. We have tested this approximation calculating the collisional cross section for the $Q(10)$ line at $440 \mathrm{~K}$ (corresponding to $389 \mathrm{~cm}^{-1}$ ). We obtain $21.5 \AA^{2}$ using the CC method and $21.2 \AA^{2}$ using CS method. Therefore we assume that approximations introduced in CS calculations are quite reasonable at least for this temperature and above. Finally, note that $E_{\text {kin }}=68,263.5,389$, and $513 \mathrm{~cm}^{-1}$ are the kinetic energies associated with the mean relative speed $\bar{v}=\sqrt{8 k_{B} T / \pi \mu}$ for the temperatures $T=77,298,440$, and $580 \mathrm{~K}$, respectively, where $\mu=1.87 \mathrm{amu}$ is the reduced mass of the colliding pair.

To compare our calculations with the experimental pressure broadening coefficients we have taken into account both forms of $\mathrm{H}_{2}$. Fortunately, the calculations can be greatly speeded up by dealing with the two forms separately, since for a given $Q\left(j_{\mathrm{A}}\right)$ line

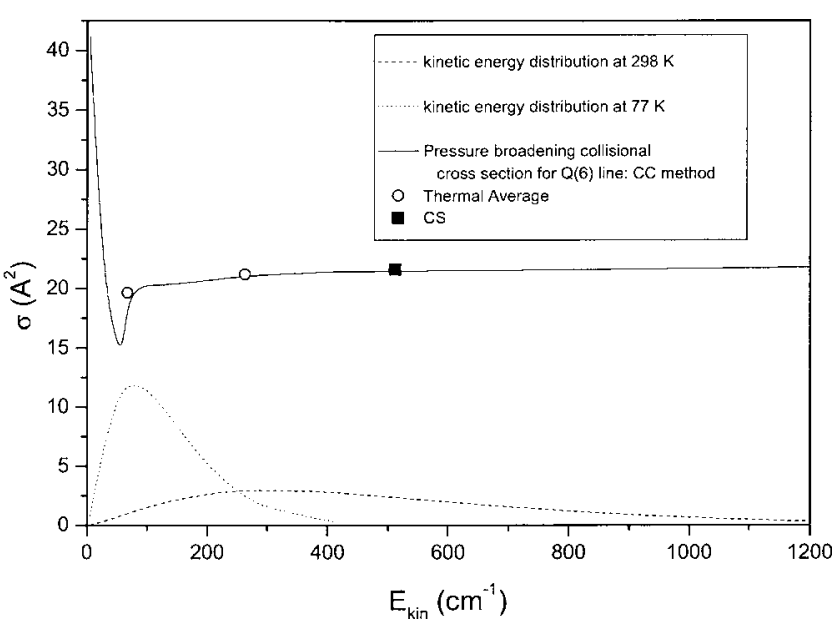

FIG. 2. Kinetic energy distribution of the perturber molecules of the system $\mathrm{N}_{2}-\mathrm{H}_{2}$ at 77 and $298 \mathrm{~K}$ (dotted and dashed lines, respectively), and pressure broadening collisional cross section for the $\mathrm{N}_{2} Q(6)$ line (solid line). The pressure broadening collisional cross section values (square) obtained by CS methods for $580 \mathrm{~K}\left(513 \mathrm{~cm}^{-1}\right)$ are also reported. The thermal averaged values (circle) of this parameter at $77 \mathrm{~K}\left(68 \mathrm{~cm}^{-1}\right)$ and $298 \mathrm{~K}\left(263.5 \mathrm{~cm}^{-1}\right)$ obtained by $\mathrm{CC}$ method are also included for comparison.

$$
\gamma\left(j_{\mathrm{A}}\right)=\frac{n_{\mathrm{H}_{2}} \bar{v}}{2 \pi c}\left\{\frac{3}{4} \sum_{j_{\mathrm{B}} \text { odd }} \rho_{j_{\mathrm{B}}} \bar{\sigma}\left(j_{\mathrm{A}}, j_{\mathrm{B}}\right)+\frac{1}{4} \sum_{j_{\mathrm{B}} \text { even }} \rho_{j_{\mathrm{B}}} \bar{\sigma}\left(j_{\mathrm{A}}, j_{\mathrm{B}}\right)\right\} .
$$

Note that the thermal average $\bar{\sigma}$ of the cross sections over the energy distribution is performed independent of the $\mathrm{H}_{2}$ unit normalized rotational populations $\rho_{J_{\mathrm{B}}}$. We have compared our calculations with the pressure broadening coefficients measured at $T=77,298,440$, and $580 \mathrm{~K}$. In the former case only the $j_{\mathrm{B}}=0$ and 1 rotational states were included in the rotational basis (in separated MOLSCAT runs), because the population of other $\mathrm{H}_{2}$ rotational levels is negligible, while at higher temperatures the first two rotational levels (for each $\mathrm{H}_{2}$ species) were included in the rotational basis.

To save CPU time we did not perform the thermal average at 298,440 , and $580 \mathrm{~K}$ because the number of energetically accessible channels dramatically increases with the kinetic energy. This is a good approximation, as we have been able to test calculating the line broadening parameter of the $Q$ (6) line at $T=298 \mathrm{~K}$ using thermal average. In this aim, calculations have been performed for higher kinetic energies $\left(410,430,450,600,800,1000\right.$, and $\left.1200 \mathrm{~cm}^{-1}\right)$ and compared to the value that we have obtained using the cross section calculated at the corresponding mean relative kinetic energy. It must be noted that we have calculated thermal average for a single line in order to test this approximation because of the high computational cost using CC method at these temperatures. For $Q(6)$ line, the calculated broadening coefficients are $50.83 \times 10^{-3} \mathrm{~cm}^{-1} / \mathrm{atm}$ for the thermal average and $50.56 \times 10^{-3} \mathrm{~cm}^{-1} / \mathrm{atm}$ in the other case. This provides a difference of only $0.53 \%$ between both values (Fig. 2). Therefore we expect this approximation to be valid for all the lines.

In order to compare the $\mathrm{CC}$ and $\mathrm{CS}$ values with the measured ones we replaced $\bar{\sigma}$ by the cross sections calculated at $E_{\mathrm{kin}}=263.5,389.0$, and $513.0 \mathrm{~cm}^{-1}$. This approxima- 
TABLE II. Comparison between experimental and theoretical [close coupling (CC) or coupled states (CS)] values of the $Q$-branch line broadening coefficients [half-width at half maximum (HWHM)] of the $\mathrm{N}_{2}-\mathrm{H}_{2}$ system for several $j$ and temperatures. All values are in $\mathrm{mk} \mathrm{atm}^{-1}\left(1 \mathrm{mk}=10^{-3} \mathrm{~cm}^{-1}\right)$.

\begin{tabular}{|c|c|c|c|c|c|c|c|c|}
\hline$j$ & $\begin{array}{l}\text { Expt. } \\
77 \mathrm{~K}\end{array}$ & $\begin{array}{c}\mathrm{CC} \\
77 \mathrm{~K}\end{array}$ & $\begin{array}{c}\text { Expt. } \\
298 \mathrm{~K}\end{array}$ & $\begin{array}{c}\text { CC } \\
298 \mathrm{~K}\end{array}$ & $\begin{array}{l}\text { Expt. } \\
440 \mathrm{~K}\end{array}$ & $\begin{array}{c}\mathrm{CC} \\
440 \mathrm{~K}\end{array}$ & $\begin{array}{c}\text { Expt. } \\
580 \mathrm{~K}\end{array}$ & $\begin{array}{c}\mathrm{CS} \\
580 \mathrm{~K}\end{array}$ \\
\hline 0 & $127.48(28.5)$ & 121.90 & $58.2(12.0)$ & 64.08 & $45.5(16.4)$ & 53.49 & $44.9(39.3)$ & 47.66 \\
\hline 1 & $82.64(16.2)$ & 74.17 & $49.5(9.8)$ & 45.85 & $36.0(11.4)$ & $\cdots$ & $50.3(17.6)$ & $\cdots$ \\
\hline 2 & $82.93(15.4)$ & 85.2 & $45.4(4.3)$ & 46.51 & $36.4(9.0)$ & 39.60 & $47.1(15.0)$ & 35.91 \\
\hline 3 & 78.11(19.5) & 89.24 & $50.6(6.9)$ & 48.29 & $41.6(10.9)$ & $\cdots$ & $36.5(17.2)$ & $\cdots$ \\
\hline 4 & $84.75(10.8)$ & 92.39 & $46.5(3.8)$ & 49.45 & $39.0(11.3)$ & 41.48 & $25.5(10.3)$ & 36.69 \\
\hline 5 & $92.69(12.1)$ & 91.90 & $44.6(5.6)$ & 50.13 & $38.4(9.0)$ & $\cdots$ & $32.1(11.8)$ & $\cdots$ \\
\hline 6 & $101.82(16.1)$ & 92.62 & 47.8(4.6) & 50.56 & $37.1(8.3)$ & 42.31 & $31.2(11.2)$ & 37.21 \\
\hline 7 & $\cdots$ & 92.62 & $51.1(5.4)$ & 50.85 & $40.1(6.5)$ & $\ldots$ & $36.5(11.4)$ & $\ldots$ \\
\hline 8 & $\cdots$ & 92.77 & $46.4(3.4)$ & 50.97 & $42.5(9.0)$ & 42.58 & $40.2(10.3)$ & 37.38 \\
\hline 9 & $\cdots$ & $\cdots$ & $50.5(4.0)$ & 50.92 & $38.9(8.1)$ & $\cdots$ & $37.4(8.3)$ & $\cdots$ \\
\hline 10 & $\cdots$ & $\cdots$ & $48.6(4.0)$ & 50.79 & $37.3(9.6)$ & 42.62 & $35.9(11.8)$ & 37.45 \\
\hline 11 & $\cdots$ & $\cdots$ & $41.5(11.2)$ & 50.47 & $42.6(6.2)$ & $\cdots$ & $43.3(10.5)$ & $\cdots$ \\
\hline 12 & $\cdots$ & $\cdots$ & $\cdots$ & $\cdots$ & $43.1(5.3)$ & $\cdots$ & $38.6(12.6)$ & 37.44 \\
\hline 13 & $\cdots$ & $\cdots$ & $\cdots$ & $\cdots$ & $40.7(9.5)$ & $\cdots$ & $34.7(14.0)$ & $\cdots$ \\
\hline 14 & $\cdots$ & $\cdots$ & $\cdots$ & 48.87 & $38.6(6.7)$ & 41.54 & $40.1(9.0)$ & 37.28 \\
\hline 15 & $\cdots$ & $\cdots$ & $\cdots$ & $\cdots$ & $42.9(9.3)$ & $\cdots$ & $32.2(11.1)$ & $\cdots$ \\
\hline 16 & $\cdots$ & $\cdots$ & $\cdots$ & $\cdots$ & $33.4(6.1)$ & $\cdots$ & $39.7(10.6)$ & 36.98 \\
\hline 17 & $\cdots$ & $\cdots$ & $\cdots$ & $\cdots$ & $32.3(19.6)$ & $\cdots$ & $30.9(13.4)$ & $\cdots$ \\
\hline 18 & $\cdots$ & $\cdots$ & $\cdots$ & $\ldots$ & $34.2(6.0)$ & 40.27 & 26.7(13.3) & 36.48 \\
\hline 19 & $\cdots$ & $\cdots$ & $\cdots$ & $\cdots$ & $\cdots$ & $\cdots$ & $22.6(17.7)$ & $\cdots$ \\
\hline 20 & $\cdots$ & $\cdots$ & $\cdots$ & $\cdots$ & $\cdots$ & $\cdots$ & $26.4(16.1)$ & 35.83 \\
\hline 21 & $\cdots$ & $\cdots$ & $\cdots$ & $\ldots$ & $\cdots$ & $\ldots$ & $39.9(9.3)$ & $\cdots$ \\
\hline 22 & $\cdots$ & $\cdots$ & $\cdots$ & $\ldots$ & $\cdots$ & $\ldots$ & $20.1(15.5)$ & 35.01 \\
\hline
\end{tabular}

tion can be expected to be quite accurate as the pressure broadening cross sections are slowly varying functions with increasing kinetic energy ${ }^{4,25,26}$ [Fig. 2 for the $Q(6)$ line].

\section{RESULTS AND DISCUSSION}

\section{A. Experimental measurements}

We have measured new experimental $Q$-branch line broadening coefficients of nitrogen perturbed by hydrogen for several values of rotational quantum numbers $j$ at temperatures of 440 and $580 \mathrm{~K}$. The technique used was stimulated Raman loss spectroscopy. To this purpose, we designed and constructed a heating cell with a system of thermal stabilization, also developed in our laboratory, allowing us to extend considerably the range of temperatures previously studied. ${ }^{4}$ In Table II, the old experimental results (77 and $298 \mathrm{~K}$ ) and the new ones (440 and $580 \mathrm{~K}$ ) are summarized.

\section{B. Ab initio PES calculation}

We have calculated a new potential energy surface for the $\mathrm{N}_{2}-\mathrm{H}_{2}$ system by testing different $a b$ initio methods and basis sets in order to know the influence of both factors on binding energies. We have chosen to build the PES with the $\operatorname{CCSD}(\mathrm{T})$ method and the Sadlej basis set augmented with midbond functions. In Fig. 3 we present potential energy curves for some selected geometries of the dimer, in particular, for the most bound linear $(L)$ one. From the fit, we get for this conformation a binding energy $D_{c}=-75.2 \mathrm{~cm}^{-1}$ for an equilibrium distance $R_{e}=4.05 \AA$. Binding energies and equilibrium distances for other conformations are presented in Table III and compared with the previous results of Salazar et $a l .^{7}$ These authors have done fourth order manybody perturbation theory (MBPT4) calculations with two different basis sets, one with the medium sized POL1 basis set of Sadlej and one with POL1 augmented with a set of midbond functions (MBFs) $[3 s 3 p 2 d]$ of Tao et al. ${ }^{11}$ We get a very good quantitative agreement with the values of Salazar et $a l^{7}{ }^{7}$ when the energies are evaluated with the set of bond functions. The largest discrepancy $\left(8 \mathrm{~cm}^{-1}\right)$ is observed for the linear absolute minimum. The agreement is only relatively good with the energies evaluated without the set of bond functions as they are always less bound and generate discrepancies up to $16 \mathrm{~cm}^{-1}$.

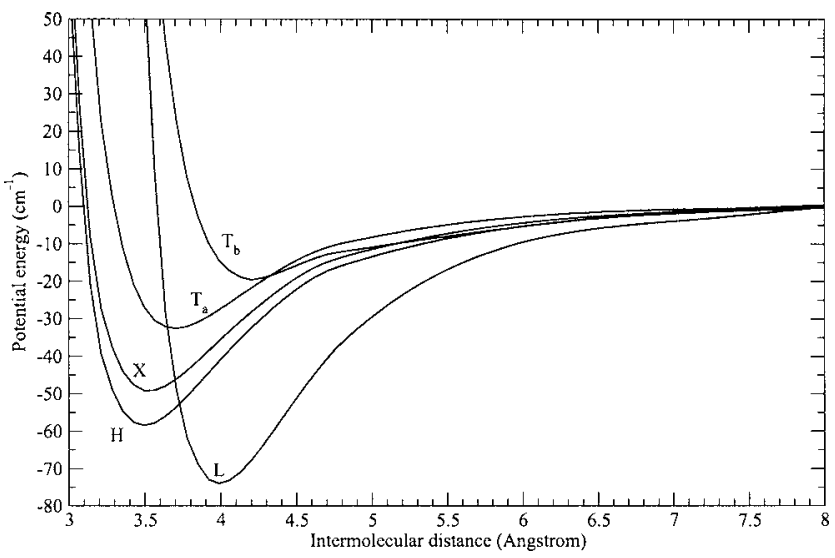

FIG. 3. Potential energy of $\mathrm{N}_{2}-\mathrm{H}_{2}$ as a function of the intermolecular distance $R$ for some selected conformations of the dimer: $\left(\theta_{\mathrm{A}}^{\mathrm{N}_{2}}, \theta_{\mathrm{B}}^{\mathrm{H}_{2}}, \varphi\right)$ $=\left(90^{\circ}, 90^{\circ}, 0^{\circ}\right)$ for $\mathrm{H},\left(0^{\circ}, 0^{\circ}, 0^{\circ}\right)$ for $\mathrm{L},\left(90^{\circ}, 90^{\circ}, 90^{\circ}\right)$ for $\mathrm{X},\left(90^{\circ}, 0^{\circ}, 0^{\circ}\right)$ for $\mathrm{T}_{a}$, and $\left(0^{\circ}, 90^{\circ}, 0^{\circ}\right)$ for $\mathrm{T}_{b}$. 
TABLE III. Binding energies and equilibrium distances of the $\mathrm{N}_{2}-\mathrm{H}_{2}$ potential obtained with the CCSD(T) method using the Sadlej basis sets augmented with midbond functions and comparison with the previous findings of Salazar et al. (Ref. 7).

\begin{tabular}{|c|c|c|c|c|c|c|}
\hline$\theta_{\mathrm{A}}^{\mathrm{N}_{2}}(\mathrm{deg})$ & $\theta_{\mathrm{B}}^{\mathrm{H}_{2}}(\mathrm{deg})$ & $\varphi(\mathrm{deg})$ & & Present work & POL1 basis ${ }^{\mathrm{a}}$ & $\mathrm{POL} 1+\mathrm{MBF}^{\mathrm{a}}$ \\
\hline \multirow[t]{2}{*}{0} & \multirow[t]{2}{*}{0} & \multirow[t]{2}{*}{0} & $R_{e}(\AA)$ & 4.05 & 4.02 & \\
\hline & & & $D_{e}\left(\mathrm{~cm}^{-1}\right)$ & -75.2 & -67.35 & -81.14 \\
\hline \multirow[t]{2}{*}{90} & \multirow[t]{2}{*}{90} & \multirow[t]{2}{*}{0} & $R_{e}(\AA)$ & 3.46 & 3.60 & \\
\hline & & & $D_{e}\left(\mathrm{~cm}^{-1}\right)$ & -58.78 & -42.42 & -59.77 \\
\hline \multirow[t]{2}{*}{90} & \multirow[t]{2}{*}{90} & \multirow[t]{2}{*}{90} & $R_{e}(\AA)$ & 3.75 & & \\
\hline & & & $D_{e}\left(\mathrm{~cm}^{-1}\right)$ & -49.13 & & \\
\hline \multirow[t]{2}{*}{90} & \multirow[t]{2}{*}{0} & \multirow[t]{2}{*}{0} & $R_{e}(\AA)$ & 3.75 & 3.86 & \\
\hline & & & $D_{e}\left(\mathrm{~cm}^{-1}\right)$ & -32.66 & -23.39 & \\
\hline \multirow[t]{2}{*}{0} & \multirow[t]{2}{*}{90} & \multirow[t]{2}{*}{0} & $R_{e}(\AA)$ & 4.23 & 4.34 & \\
\hline & & & $D_{e}\left(\mathrm{~cm}^{-1}\right)$ & -19.48 & -15.97 & \\
\hline \multirow[t]{2}{*}{45} & \multirow[t]{2}{*}{45} & \multirow[t]{2}{*}{0} & $R_{e}(\AA)$ & 3.92 & 4.07 & \\
\hline & & & $D_{e}\left(\mathrm{~cm}^{-1}\right)$ & -28.39 & -20.49 & -28.96 \\
\hline \multirow[t]{2}{*}{22.5} & \multirow[t]{2}{*}{67.5} & \multirow[t]{2}{*}{0} & $R_{e}(\AA)$ & 4.13 & & \\
\hline & & & $D_{e}\left(\mathrm{~cm}^{-1}\right)$ & -22.31 & & \\
\hline
\end{tabular}

${ }^{\mathrm{a}}$ Reference 7 .

Present results confirm previous findings of Salazar et $a .^{7}$ Our findings are that the linear conformation is the most stable one, followed by the planar and parallel $(\mathrm{H})$ configuration, then followed by the crossed (X) conformation, and finally, by the $\mathrm{T}$ shaped structures, which are the less bounded with binding energies of 33 and $19 \mathrm{~cm}^{-1}$ for $\mathrm{H}_{2}$ pointing toward $\mathrm{N}_{2}$ and conversely, i.e., $(\mathrm{L}>\mathrm{H}>\mathrm{X}>\mathrm{T})$.

\section{Quantum line broadening calculations}

Using the PES described above, we have computed pressure broadening coefficients of $\mathrm{N}_{2}$ Raman isotropic $Q$ branch at the temperatures of 77, 298, 440, and $580 \mathrm{~K}$. In Table II and in Fig. 4, we present a summary of experimental and quantum line broadening coefficients for all the considered temperatures. It must be noted that the experimental values of the line broadening coefficient with the lowest and highest $j$ values present larger error bars. It is due to the fact that these lines are the less intense ones of the spectrum for each studied temperature, and therefore they present the worst signal to noise ratio. In these cases, comparison between experience and theory is less significant than for the other lines considered. The relative average differences between experiment and calculations are $7.2 \%$ for 77 and $298 \mathrm{~K}, 10.7 \%$ for $440 \mathrm{~K}$, and $22.3 \%$ for $580 \mathrm{~K}$. If we do not consider the values corresponding to the first and last $j$ for each temperature the differences are $7.4 \%$ for $77 \mathrm{~K}, 5.5 \%$ for $298 \mathrm{~K}, 10.1 \%$ for $440 \mathrm{~K}$, and $18.7 \%$ for $580 \mathrm{~K}$. The theoretical results are in very good agreement with experimental ones, taking into account the error bars of the experimental values, though as it can be seen, the agreement is better at lower temperatures. Theoretical calculations provide an interesting test of the potential energy surface presented in this work. The magnitude and temperature dependence are well reproduced for all $j$ numbers in the whole range of temperatures. Further checks of the quality of this PES on the comparison between calcu- lated and experimental second virial coefficients and scattering cross sections will be published in a forthcoming paper. ${ }^{27}$

\section{CONCLUSION}

We have presented a detailed study of pressure broadening coefficients of nitrogen Raman $Q$-branch lines perturbed by $\mathrm{H}_{2}$. For that purpose, new experimental and theoretical results concerning the $\mathrm{N}_{2}-\mathrm{H}_{2}$ system have been obtained. Line broadening coefficients are measured by the precise stimulated Raman loss spectroscopy technique and compared to calculations performed using quantum calculations on a new $a b$ initio potential energy surface.

As it was discussed in a previous work, ${ }^{4}$ the theoretical collisional line broadening coefficients, obtained from the semiclassical Robert-Bonamy model using an analytical atom-atom potential for the $\mathrm{N}_{2}-\mathrm{H}_{2}$ system at 77 and $298 \mathrm{~K}$, show a discrepancy with respect to the experimental values, mainly for $77 \mathrm{~K}$. For low temperatures, semiclassical approaches are not well adapted for line broadening calculations due to contribution of orbiting collisions not taken into account in the model. In this case, only pure quantum methods (as CC or CS) can be used. Indeed, comparison between experimental data $(77-580 \mathrm{~K})$ and the theoretical results carried out in this work shows that the new potential energy surface presented in this paper allows us to reproduce quite well the broadening coefficients and their temperature dependence.

Temperature diagnostic in combustion media requires high temperature broadening coefficients, but due to the computational cost for pure quantum calculations ( $\mathrm{CC}$ or $\mathrm{CS}$ methods) at high temperatures, only semiclassical approaches ${ }^{5}$ are feasible. Following the previous work ${ }^{4}$ done with the Robert-Bonamy approach, new calculations must be performed to determine the temperature dependence of line 

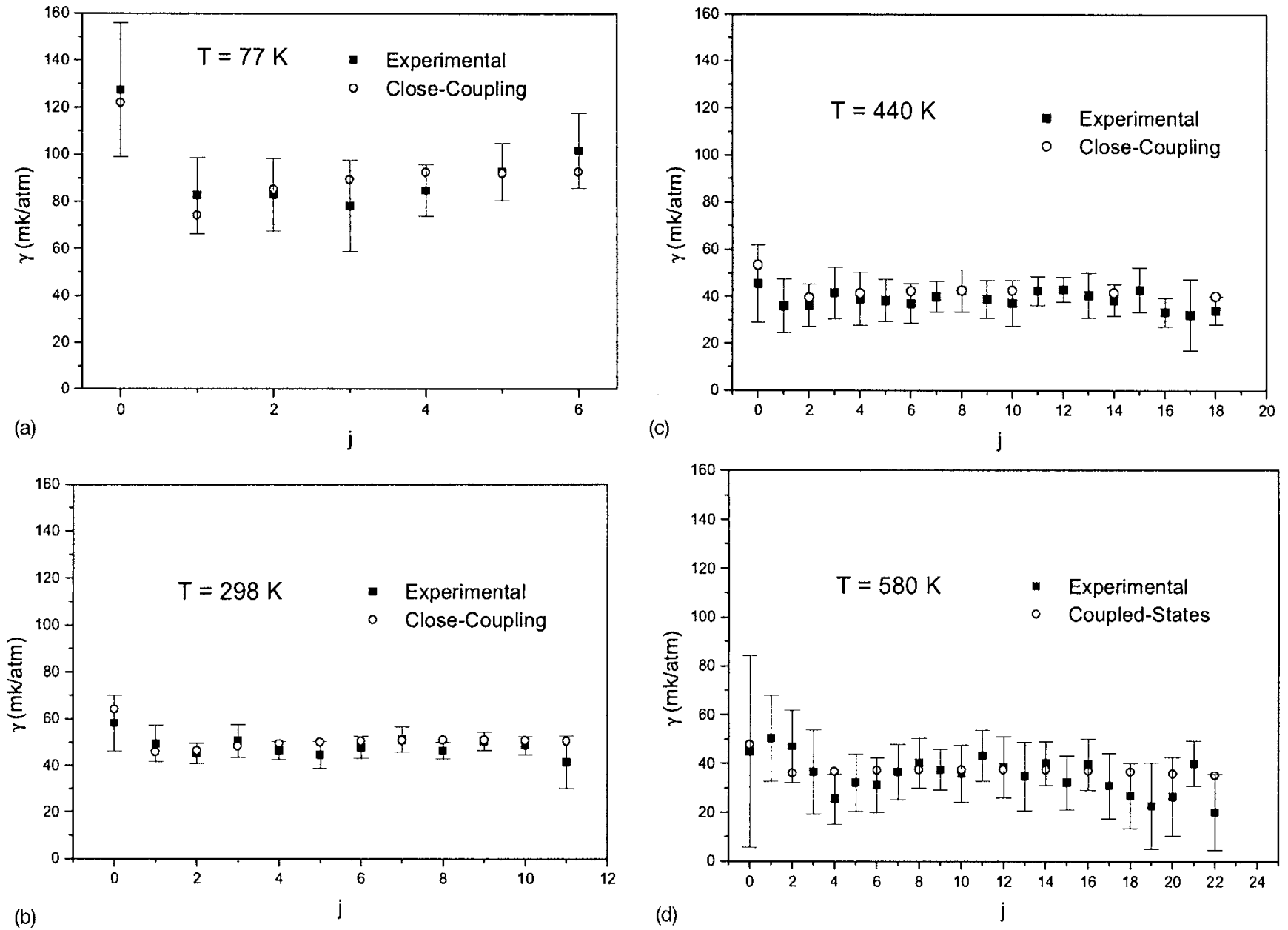

FIG. 4. Comparison between experimental and theoretical values of the $Q$-branch line broadening coefficient (HWHM) for several $j$, in $\mathrm{mk} \mathrm{atm}^{-1}$, (a) for $T=77 \mathrm{~K}$, (b) for $T=298 \mathrm{~K}$, (c) for $T=440 \mathrm{~K}$, and (d) for $T=580 \mathrm{~K}$.

broadening coefficients at high temperatures (up to $2500 \mathrm{~K}$ ). Due to the satisfactory results obtained with the present $a b$ initio PES, these calculations require the implementation of this potential in the RB model. This work is in progress and will be presented in a future paper.

\section{ACKNOWLEDGMENTS}

The authors would like to thank the Institut du Développement et des Ressources en Informatique Scientifique (IDRIS, CNRS) for providing the authors with the computer power as well as the "Pôle de Calcul Informatique de l'Ouest (PCIO)" located in Rennes. Three of the authors (L. G., R. M., and D. B.) would like to thank Robert Saint-Loup for kindly providing technical information for the construction of the high temperature cell, and Javier Rodriguez for design and construction of the electronic stabilization. Finally the said authors (L. G., R. M., and D. B.) also acknowledge financial support from Spanish DGI under Project No. FIS2005-02029.

\footnotetext{
${ }^{1}$ B. Lavorel, G. Millot, R. Saint-Loup, C. Wegner, H. Berger, J. P. Sala, J. Bonamy, and D. Robert, J. Phys. (Paris) 47, 417 (1986).

${ }^{2}$ L. A. Rahn and R. E. Palmer, J. Opt. Soc. Am. B 3, 1164 (1986).
}

${ }^{3}$ J. Bonamy, L. Bonamy, D. Robert, M. L. Gonze, G. Millot, B. Lavorel, and H. Berger, J. Chem. Phys. 94, 6584 (1991).

${ }^{4}$ L. Gomez, D. Bermejo, P. Joubert, and J. Bonamy, Mol. Phys. 104, 1869 (2006).

${ }^{5}$ D. Robert and J. Bonamy, J. Phys. (Paris) 40, 923 (1979).

${ }^{6}$ D. Bermejo, J. Santos, P. Cancio, J. L. Doménech, C. Domingo, J. M. Orza, J. Ortigoso, and R. Escribano, J. Raman Spectrosc. 21, 197 (1990).

${ }^{7}$ M. C. Salazar, J. L. Paz, and A. J. Hernandez, J. Mol. Struct.: THEOCHEM 464, 183 (1999).

${ }^{8}$ S. P. Walch, J. Chem. Phys. 91, 389 (1989).

${ }^{9}$ J. R. Stallcop, H. Partridge, and E. Levin, Phys. Rev. A 62, 062709 (2000).

${ }^{10}$ SAPT, a program for many-body symmetry-adapted perturbation theory calculations of intermolecular interaction energies, 1999; B. Jeziorski, R. Moszynski, A. Ratkiewicz, S. Rybak, K. Szalewicz, H. L. Williams, B. Jeziorski, R. Moszynski, and K. Szalewicz, Chem. Rev. (Washington, D.C.) 94, 1887 (1994); R. Moszynski, P. E. S. Wormer, and A. van der Avoird, in Computational Molecular Spectroscopy, edited by P. R. Bunker and P. Jensen (Wiley, New York, 2000), p. 69.

${ }^{11}$ F. M. Tao and Y. K. Pan, Mol. Phys. 81, 507 (1994); J. Chem. Phys. 100, 4947 (1994).

${ }^{12}$ S. F. Boys and F. Bernardi, Mol. Phys. 19, 553 (1970).

${ }^{13}$ H.-J. Werner, P. J. Knowles, R. D. Amos et al., MOLPRO version 2002, a package of ab initio programs.

${ }^{14}$ K. T. Tang and J. P. Toennies, J. Chem. Phys. 80, 3726 (1984).

${ }^{15}$ R. Bukowski, J. Sadlej, B. Jeziorski, P. Jankowski, K. Szalewicz, S. A. Kucharski, H. L. Williams, and B. M. Rice, J. Chem. Phys. 110, 3785 (1999).

${ }^{16}$ R. Bukowski, J. Sadlej, B. Jeziorski, P. Jankowski, K. Szalewicz, S. A. Kucharski, H. L. Williams, and B. M. Rice, ASYMP-SAPT package, University of Delaware and University of Warsaw. 
${ }^{17}$ A. Ben-Reuven, Phys. Rev. 141, 34 (1966); 145, 7 (1966).

${ }^{18}$ R. Shafer and R. G. Gordon, J. Chem. Phys. 58, 5422 (1973).

${ }^{19}$ J. M. Hutson and S. Green, MOLSCAT version 14, Collaborative Computational Project 6 of the UK Science and Engineering Research Council, Daresbury Laboratory, UK, 1995.

${ }^{20}$ M. Baranger, Phys. Rev. 111, 481 (1958); 112, 855 (1958).

${ }^{21}$ U. Fano, Phys. Rev. 131, 259 (1963).

${ }^{22}$ M. H. Alexander and D. E. Manolopoulos, J. Chem. Phys. 86, 2044 (1987).

${ }^{23}$ S. Green, J. Chem. Phys. 62, 2271 (1975).

${ }^{24}$ W. H. Press, B. P. Flannery, S. A. Teukolsky, and W. T. Vetterling, $\mathrm{Nu}$ merical Recipes in Fortran 77, The Art of Scientific Computing (Cam- bridge University Press, Cambridge, 1992), Chap. 4.

${ }^{25}$ F. Thibault, B. Calil, J. Buldyreva, M. Chrysos, J. M. Hartmann, and J. P. Bouanich, Chem. Phys. 3, 3924 (2001).

${ }^{26}$ F. Thibault, R. Z. Martinez, J. L. Domenech, D. Bermejo, and J. P. Bouanich, Chem. Phys. 117, 2523 (2002).

${ }^{27}$ L. Gomez, T. Cauchy, M. Bartolomei, D. Cappelletti, F. Pirani, and B. Bussery-Honvault, Chem. Phys. Lett. (unpublished).

${ }^{28}$ See EPAPS Document No. E-JCPSA6-126-017718 for the potential routines including the coefficients. This document can be reached via a direct link in the online article's HTML reference section or via the EPAPS homepage (http://www.aip.org/pubservs/epaps.html). 